\title{
Fertilização com fosfato natural e cinética de absorção de fósforo de soja e plantas de cobertura do cerrado
}

\section{Fertilization with rock phosphate and kinetics of phosphorus uptake by soybean and cover crops of Brazilian cerrado soils}

\author{
Evandro Luiz Schoninger ${ }^{*}$; Luciano Colpo Gatiboni²; Paulo Roberto Ernani ${ }^{2}$
}

\section{Resumo}

A fim de identificar plantas com maior capacidade de absorção de $\mathrm{P}$ em solos de cerrado adubados com fosfato natural, visando a ciclagem deste nutriente, objetivou-se: a) avaliar a capacidade de absorção de fósforo e o desenvolvimento inicial de soja, sorgo, milheto e braquiária em função da aplicação de fosfato solúvel e natural ao solo; b) estimar os parâmetros cinéticos de absorção de $\mathrm{P}$ dessas espécies cultivadas em solução nutritiva. Para tanto, foram realizados dois experimentos no Centro de Ciências Agroveterinárias da Universidade do Estado de Santa Catarina (CAV/UDESC), no ano de 2010. O primeiro experimento constou do desenvolvimento de plantas (soja, braquiária, sorgo e milheto) em solos adubados com fosfato natural e superfosfato triplo, além de um tratamento sem aplicação de $\mathrm{P}$, arranjados em um fatorial $4 \times 3$, sob delineamento inteiramente casualizado, com quatro repetições. Foram avaliadas a produção de massa seca das plantas e a quantidade de $\mathrm{P}$ acumulada no tecido. No segundo experimento foram estimados os parâmetros cinéticos de absorção de $\mathrm{P}\left(\mathrm{I}_{\max }, \mathrm{K}_{\mathrm{m}}\right.$ e $\left.\mathrm{C}_{\text {min }}\right)$ de cada uma das espécies após 23 dias de desenvolvimento em solução nutritiva, utilizando-se o delineamento inteiramente casualizado com quatro repetições. A soja, em fase inicial de desenvolvimento, não responde à adubação fosfatada, apresentando mais massa seca de tecido e acúmulo de $\mathrm{P}$ no tecido, comparativamente às demais espécies. A aplicação de superfosfato triplo promoveu maior produção de massa seca de tecido para todas as gramíneas, quando comparada às demais fontes de P. A braquiária apresentou maior taxa de absorção de $\mathrm{P}$ em elevadas concentrações deste nutriente na solução, enquanto a soja apresentou maior capacidade de absorção de P em baixas concentrações na solução.

Palavras-chave: Parâmetros cinéticos de absorção, ciclagem de fósforo, adubação fosfatada

\begin{abstract}
In order to identify plants with greater capacity of $\mathrm{P}$ uptake in Cerrado soils fertilized with phosphate rock this work was carried out with the following objectives: a) to evaluate the phosphorus (P) uptake and initial development of soybean, brachiaria, sorghum and millet in soils fertilized with soluble and rock phosphates; b) to estimate the kinetic parameters of $\mathrm{P}$ uptake for each species. Two experiments were conducted at Santa Catarina State University, Brazil, in the year of 2010. The first experiment consisted of plant development under the application of phosphate fertilizers to the soil. Treatments consisted of growth of four plant species (soybean, brachiaria, sorghum and millet) as affected by application of rock phosphate, triple superphosphate, and a control without $P$. The four replications were arranged in a $4 \times 3$ factorial using a completely randomized design. It was evaluated the plant dry matter yield and $\mathrm{P}$ accumulated in plant tissue. In the second experiment, we estimated the kinetic parameters of $\mathrm{P}$
\end{abstract}

\footnotetext{
${ }^{1}$ Eng $^{\circ}$ Agr $^{\circ}$, Doutorando em Ciências, Centro de Energia Nuclear na Agricultura/Universidade de São Paulo, CENA/USP, Laboratório de Isótopos Estáveis, São Dimas, Piracicaba, SP. E-mail: schoningerel@gmail.com

${ }^{2}$ Engenheiros Agrônomos, Profs. do Dept ${ }^{\circ}$ de Agronomia, Centro de Ciências Agroveterinárias, Universidade do Estado de Santa Catarina, CAV/UDESC, Conta Dinheiro, Lages, SC. E-mail: lgatiboni@gmail.com; a2pre@cav.udesc.br

* Autor para correspondência
} 
uptake ( $\mathrm{I}_{\max }, \mathrm{K}_{\mathrm{m}}$ and $\mathrm{C}_{\text {min }}$ ) of each species after 23 days of growth in solution culture, using a completely randomized design with four replications. Soybean did not respond to fertilization, but presents the highest dry mass yield and the greatest accumulation of $\mathrm{P}$ in the tissue. Triple superphosphate is the $\mathrm{P}$ source that caused the greatest dry matter yield for all gramineous species. Brachiaria has a higher rate of $\mathrm{P}$ uptake at high concentrations of this nutrient in the solution, while the soybean has a greater capacity for P uptake at low concentrations in solution.

Key words: Kinetics parameters of uptake, phosphorus cycling, phosphorus fertilization

\section{Introdução}

Para adequada nutrição da cultura da soja em solos do Cerrado brasileiro, se faz necessária a utilização de elevadas doses de fertilizantes, devido ao predomínio de solos altamente intemperizados, caracterizados pela baixa disponibilidade de nutrientes às plantas. Neste contexto, o $\mathrm{P}$ merece especial atenção por causa da sua grande adsorção à fase mineral do solo, predominantemente de baixa reversibilidade, principalmente nos óxidos de $\mathrm{Fe}$ e Al. Assim, apesar deste nutriente ser exigido em pequenas quantidades pela maioria das culturas, tem-se aplicado grandes doses de P para obter teores adequados de $\mathrm{P}$ disponível e suprir as necessidades dos cultivos (SOUSA; LOBATO; REIN, 2004), utilizando-se principalmente adubos fosfatados solúveis. Como os custos de fabricação desses fosfatos são elevados, tem-se observado interesse no uso de fontes alternativas de $\mathrm{P}$, com destaque aos fosfatos naturais, que apresentam menor custo por unidade de $\mathrm{P}$, mas proporcionam baixa disponibilidade de $\mathrm{P}$ às plantas em curto prazo. Para que os fosfatos naturais disponibilizem o P no solo, é necessário que ocorra sua solubilização, sendo esta, dependente da origem do fosfato, das propriedades do solo, das práticas de manejo e da espécie vegetal cultivada (ARCAND; SCHNEIDER, 2006; NYING; ROBINSON, 2006).

A adequada nutrição das culturas, além de depender da fonte de fósforo utilizada como fertilizante, também esta relacionada à habilidade de absorção de P pelas plantas, característica esta, dependente dos parâmetros cinéticos de absorção de cada espécie/cultivar (BHADORIA et al., 2004; HORN et al., 2006). Por meio do cultivo de plantas em solução nutritiva é possível obter estimativas desses parâmetros, sendo: o influxo máximo $\left(\mathrm{I}_{\max }\right)$, a concentração de nutriente na solução em que ocorre a metade do $I_{\max }\left(K_{m}\right)$ e a concentração mínima de nutriente na solução para que ocorra absorção deste $\left(\mathrm{C}_{\text {min }}\right)$.

Como a maioria dos produtores de soja no Brasil faz uso do sistema de plantio direto, tornase indispensável o cultivo de plantas de cobertura no período de entressafra para produção de palhada. Assim, por meio da escolha adequada dessas plantas, visando maior habilidade de absorção de $\mathrm{P}$, pode-se aumentar a disponibilidade de $\mathrm{P}$ para as culturas sucessoras (OLIVEIRA et al., 2005; RAMOS et al., 2010). Isto ocorre, porque o P oriundo de fosfatos naturais e/ou presente em formas pouco disponíveis no solo, que na maioria dos casos estaria indisponível para grande parte das culturas produtoras de grãos, é convertido em formas orgânicas após ser absorvido, e poderá estar mais disponível para as lavouras em sucessão, após ocorrer a mineralização do $\mathrm{P}$ orgânico dos restos vegetais (SOUSA; LOBATO; REIN, 2004). Deste modo, diversos trabalhos (OLIVEIRA et al., 2005; FOLONI et al., 2008; RAMOS et al., 2010) têm destacado algumas espécies como promissoras, tanto em relação à absorção de $\mathrm{P}$ em condições de baixa disponibilidade, bem como no uso eficiente deste nutriente.

Dentre as espécies cultivadas no Cerrado, a soja destaca-se como principal cultura produtora de grãos, e o milheto tem sido utilizado como planta de cobertura no período de entressafra. Contudo, outras espécies como o sorgo e a braquiária têm apresentado potencial para utilização como planta 
de cobertura nesta região. Assim, o presente trabalho objetivou avaliar a capacidade de absorção de fósforo e o desenvolvimento inicial de soja, sorgo, milheto e braquiária em função da aplicação de fosfato solúvel e natural ao solo, bem como estimar os parâmetros cinéticos de absorção de $\mathrm{P}$ dessas espécies cultivadas em solução nutritiva.

\section{Material e Métodos}

Foram realizados dois experimentos durante o período de janeiro a novembro de 2010, na Universidade do Estado de Santa Catarina - Centro de Ciências Agroveterinárias, na cidade de Lages, $\mathrm{SC}$.

Para a condução do primeiro experimento, utilizou-se amostra de um solo coletado na camada de 0-20 cm de um Latossolo Vermelho-Amarelo Distrófico, de textura argilosa, que estava sob cultivo com pastagem de Brachiaria brizantha no município de Matupá - MT (latitude 10¹0'18" S e longitude 5451'33" O). O solo foi seco ao ar, passado em peneira com malha de $2 \mathrm{~mm}$ de abertura, e apresentava as seguintes características: pH em água: 5,4; $\mathrm{P}$ (Mehlich 1): $0,5 \mathrm{mg} \mathrm{dm}^{-3}$; $\mathrm{K}$ : 1,4 $\mathrm{mmol}_{\mathrm{c}} \mathrm{dm}^{-3}$; $\mathrm{Ca}: 7,0 \mathrm{mmol}_{\mathrm{c}} \mathrm{dm}^{-3} ; \mathrm{Mg}$ 4,2 $\mathrm{mmol}_{\mathrm{c}}$ $\mathrm{dm}^{-3}$; Al: 4,2 $\mathrm{mmol}_{\mathrm{c}} \mathrm{dm}^{-3}$; H+Al: $54,8 \mathrm{mmol}_{\mathrm{c}} \mathrm{dm}^{-3}$; matéria orgânica: $30 \mathrm{~g} \mathrm{dm}^{-3} ; \mathrm{CTC}_{(\mathrm{pH} 7,0)}: 67,4 \mathrm{mmol}_{\mathrm{c}}$ $\mathrm{dm}^{-3}$; saturação por bases (V): $19 \%$; areia: $296 \mathrm{~g}$ $\mathrm{kg}^{-1}$; silte: $165 \mathrm{~g} \mathrm{~kg}^{-1}$; argila: $538 \mathrm{~g} \mathrm{~kg}^{-1}$.

Visando elevar a saturação por bases do solo a $50 \%$, conforme recomendação de Sousa e Lobato (2004), realizou-se a aplicação e incorporação de 1,2 g de calcário dolomítico (filler) por kg de solo, dose esta equivalente a 2,4 $\mathrm{t} \mathrm{ha}^{-1}$. Em seguida, o solo foi incubado por 20 dias com umidade próxima a capacidade de campo, com a finalidade de proporcionar a reação das partículas do calcário com o solo. Posteriormente, o solo foi seco, subdividido em 48 amostras de $400 \mathrm{~g}$ e acondicionado em vasos de $500 \mathrm{~cm}^{3}$.

$$
\text { Utilizou-se o delineamento experimental }
$$

inteiramente casualizado, com 4 repetições. Os tratamentos, arranjados em esquema fatorial $3 \times 4$, constaram da aplicação de duas fontes de fósforo (fosfato natural reativo de Arad-Arad, e superfosfato triplo - SFT), além de uma testemunha sem P, e do cultivo de quatro espécies de plantas (Glycine max (L.) Merrill - soja, Brachiaria brizantha Hochst Stapf - braquiária, Pennisetum glaucum (L.) R. Brown - milheto e Sorghum bicolor (L.) Moench - sorgo). Com exceção do tratamento testemunha, as demais unidades experimentais receberam a aplicação e incorporação de dose equivalente a 140 $\mathrm{kg} \mathrm{ha}{ }^{-1}$ de $\mathrm{P}_{2} \mathrm{O}_{5}\left(28 \mathrm{mg}\right.$ vaso ${ }^{-1}$ de $\left.\mathrm{P}_{2} \mathrm{O}_{5}\right)$ a partir das fontes de fósforo representantes de cada tratamento, conforme recomendação de Sousa e Lobato (2004). Em seguida, realizou-se a semeadura de três sementes viáveis de cada espécie, previamente germinadas em folhas de papel umedecidas e, selecionadas apenas as sementes que apresentavam emissão da radícula. Visando obter o teor de P nas sementes de cada espécie, realizou-se a secagem de três amostras de cada espécie em estufa a $65^{\circ} \mathrm{C}$, seguido de digestão sulfúrica descrita por Tedesco et al. (1995), e determinação da concentração de P no extrato pelo método colorimétrico proposto por Murphy e Riley (1962).

Após a aplicação dos tratamentos, os vasos foram acondicionados em casa-de-vegetação, e a umidade do solo foi mantida próxima a $70 \%$ da capacidade de campo, por meio de regas diárias com base na diferença de peso das unidades experimentais. No dia da semeadura, as unidades experimentais receberam a aplicação de $25 \mathrm{mg} \mathrm{kg}^{-1}$ de $\mathrm{N}$ (exceto para a soja) e $50 \mathrm{mg} \mathrm{kg}^{-1}$ de $\mathrm{K}$ via solução, a partir das fontes uréia e cloreto de potássio, respectivamente. Nos vasos onde a soja foi semeada, realizou-se a aplicação de inoculante líquido (Bradyrhizobium japonicum), na dose correspondente a $200 \mathrm{~mL} \mathrm{ha}^{-1}$. Aos 5 dias após a semeadura, foi realizado o desbaste das plantas, deixando-se apenas uma planta por vaso. Aos 14 dias após a semeadura, foi realizada a aplicação, via solução, de $25 \mathrm{mg} \mathrm{kg}^{-1}$ de $\mathrm{N}$ aos vasos (exceto para a soja). 
Aos 28 dias após a semeadura, procedeu-se o corte da parte aérea das plantas rente à superfície do solo e, em seguida, as raízes de cada vaso foram separadas do solo. Tanto a parte aérea como as raízes das plantas foram secas em estufa a $65^{\circ} \mathrm{C}$ até peso constante, e posteriormente pesadas para a determinação da massa seca (MS). Para avaliar o teor de fósforo nos tecidos das plantas (parte aérea e raiz), foi realizada a digestão sulfúrica, e para estimar o fósforo disponível no solo foi realizada a extração por resina de troca aniônica, em lâminas, conforme metodologia descrita por Tedesco et al. (1995). Para a determinação do fósforo nos extratos, tanto do tecido vegetal como do solo, utilizou-se o método colorimétrico proposto por Murphy e Riley (1962).

Com base nos valores de produção de MS de parte aérea e de raízes, procedeu-se o cálculo da relação raiz/parte aérea e, relacionando-se a produção de $\mathrm{MS}$ com as concentrações de $\mathrm{P}$ no tecido das plantas, obteve-se a quantidade total de $\mathrm{P}$ acumulada pelas espécies. Com os valores de $\mathrm{P}$ acumulados no tecido (parte aérea e raízes) de cada espécie, foi calculada a eficiência relativa (ER) do fosfato reativo de Arad em relação ao SFT, por meio da seguinte equação: $E R=[(y 2-y 1) /(y 3-y 1)]$ $\mathrm{x} 100$, onde: $\mathrm{y} 2$ = fósforo acumulado no tecido no tratamento com fosfato reativo de Arad; y1 = fósforo acumulado no tecido no tratamento sem aplicação de P e; y3 = fósforo acumulado no tecido no tratamento com superfosfato triplo (valor de referência).

No segundo experimento, os tratamentos constaram do cultivo das quatro espécies do primeiro experimento, em delineamento experimental inteiramente casualizado com quatro repetições. Sementes de cada espécie foram germinadas entre folhas de papel-toalha com base imersa numa solução com $0,2 \%$ de Ca. Sete dias após a semeadura, foram selecionadas quatro plantas de cada espécie por repetição (similares quanto ao desenvolvimento da parte aérea e do sistema radicular) e, em seguida, foram transplantadas em vasos plásticos contendo quatro litros de solução nutritiva. Esses vasos foram transferidos para câmara de crescimento, ajustada para fotoperíodo diário de 12 horas, com temperatura de $30^{\circ} \mathrm{C}, 75 \%$ de umidade relativa do ar e radiação fotossinteticamente ativa ao nível da planta de $350 \mu \mathrm{mol} \mathrm{m} \mathrm{m}^{-2} \mathrm{~s}^{-1}$. As 12 horas de escuro foram conduzidas com $25^{\circ} \mathrm{C}$ e umidade relativa do ar de $85 \%$. Na primeira semana após o transplante, empregou-se a metade da concentração da solução nutritiva de Hoagland e Arnon (1950), e a partir da segunda semana utilizou-se a concentração integral, sendo a solução substituída duas vezes por semana e seu pH ajustado diariamente para 5,5 $\pm 0,2$.

Os parâmetros cinéticos de absorção, ou seja, o influxo máximo $\left(\mathrm{I}_{\max }\right)$, a constante de Michaelis Menten $\left(\mathrm{K}_{\mathrm{m}}\right)$, que equivale à concentração de nutriente na solução em que ocorre a metade do $\mathrm{I}_{\max }$, e a concentração abaixo da qual as plantas deixam de absorver os nutrientes $\left(\mathrm{C}_{\text {min }}\right)$ foram determinados pelo princípio descrito por Claassen e Barber (1974), o qual consiste na quantificação da diminuição da concentração do nutriente na solução de acordo com a absorção. Para tanto, aos 22 dias após a semeadura, as plantas foram transferidas para vasos contendo quatro litros de água destilada com a finalidade de elevar a capacidade de absorção de P. Após a permanência em água destilada por 24 horas, estas plantas retornaram a solução nutritiva contendo a concentração integral dos nutrientes, exceto para o $\mathrm{P}$, o qual teve sua concentração ajustada para $15 \mu \mathrm{mol} \mathrm{L} \mathrm{L}^{-1}$. Esta concentração foi estimada com base na quantidade de $\mathrm{P}$ absorvida pelas plantas em 24 horas em ensaio prévio. As plantas permaneceram nesta solução por uma hora, para que o sistema atingisse as condições de estado estacionário de absorção requeridas para a aplicação do modelo cinético, e então foram transferidas para uma nova solução contendo as mesmas concentrações de nutrientes, inclusive com o ajuste do P para $15 \mu \mathrm{mol} \mathrm{L}{ }^{-1}$. Em seguida, iniciouse a coleta de alíquotas $(10 \mathrm{~mL})$ da solução de cada vaso, em intervalos de uma hora, durante dez horas. Após 24 horas do início da coleta das alíquotas, procederam-se mais três coletas intercaladas em 
três horas para se ter certeza da obtenção do $\mathrm{C}_{\text {mín }}$ das diferentes espécies. A determinação dos teores de $\mathrm{P}$ nas alíquotas foi realizada empregando-se o método colorimétrico proposto por Murphy e Riley (1962). A evapotranspiração de água dos vasos durante as dez horas de coleta foi estimada com base na diferença de peso do conjunto (vaso + solução + plantas) entre o início e o fim das coletas. Ao término da coleta das alíquotas, procedeu-se a coleta e secagem das raízes em estufa a $65^{\circ} \mathrm{C}$ até peso constante, para determinação da massa seca.

Os valores dos parâmetros cinéticos $\mathrm{I}_{\max }$ e $\mathrm{K}_{\mathrm{m}}$ foram calculados por meio do programa Cinética (RUIZ; FERNANDES FILHO, 1992), que se baseia no princípio desenvolvido por Claassen e Barber (1974). O C $_{\text {mín }}$ foi estimado a partir da última coleta, realizada 30 horas após o início do processo de retirada das alíquotas.

Os dados do primeiro experimento foram transformados em $\mathrm{z}=(\mathrm{y}+3 / 8)^{0,5}$ visando à obtenção de normalidade e homogeneidade de variância (BANZATO; KRONKA, 2006). Em seguida, realizou-se a análise de variância dos dados de ambos os experimentos $(p \leq 0,05)$, e quando observado efeito significativo, as médias dos tratamentos foram comparadas pelo teste de Tukey a 5\% de significância.

\section{Resultados e Discussão}

Houve interação entre as fontes de $\mathrm{P}$ e as espécies cultivadas para massa seca da parte aérea (MSPA) e relação raiz/parte aérea (RRPA) (Tabela 1), optando-se pelo desdobramento e análise dos efeitos simples nestas variáveis (Tabela 2). Para massa seca de raízes (MSR), fósforo acumulado no tecido (PAC) e fósforo disponível no solo (PDS) restringiu-se a análise apenas dos efeitos principais (Tabela 1).
$\mathrm{Na}$ comparação das espécies em cada fonte fosfatada, observou-se superioridade na produção de MSPA com o cultivo da soja em relação às demais culturas, em todas as fontes testadas (Tabela 2). Ao analisarmos os efeitos das fontes de $P$ na MSPA em cada espécie, observou-se que a soja foi a única cultura não influenciada pelas fontes de $\mathrm{P}$, enquanto as demais apresentaram maior produção de MSPA com a aplicação do SFT, e a utilização de Arad não diferiu da testemunha. Para MSR (Tabela 1), a aplicação de SFT proporcionou maiores valores quando comparada aos tratamentos Arad e testemunha. Dentre as espécies, novamente a soja destacou-se com maiores valores de MSR frente às demais (Tabela 1). Esta ausência de resposta às fontes de $\mathrm{P}$ por parte da soja e sua consequente superioridade em relação às demais espécies quanto à produção de MSPA e MSR evidenciam, que em seu desenvolvimento inicial, o fornecimento de P para esta planta não é dependente do solo. Neste caso, até 28 dias após a semeadura, a provável origem do P para o desenvolvimento inicial desta cultura foi a própria semente, tendo em vista a elevada quantidade de $\mathrm{P}$ por semente $\left(0,465 \mathrm{mg}\right.$ semente $\left.^{-1}\right)$ em relação à braquiária $\left(0,023 \mathrm{mg}\right.$ semente $\left.^{-1}\right)$, ao sorgo $\left(0,064 \mathrm{mg} \mathrm{semente}^{-1}\right)$ e ao milheto $(0,021 \mathrm{mg}$ semente $\left.{ }^{-1}\right)$. Esta relação positiva entre a quantidade de $\mathrm{P}$ na semente e a produção de massa seca das plantas já foi relatada para soja (TRIGO et al., 1997), trigo (ZHU; SMITH, 2001) e arroz (ROS; BELL; WHITE, 1997), confirmando a hipótese de que no início de seu desenvolvimento, determinadas espécies de plantas podem sobreviver apenas com o $P$ oriundo da semente. 
Tabela 1. Massa seca da parte aérea (MSPA), massa seca de raízes (MSR), relação raiz/parte aérea (RRPA), fósforo acumulado no tecido (PAC) e fósforo disponível no solo (PDS) em função de fontes de fósforo e espécies vegetais cultivadas.

\begin{tabular}{lccccc}
\hline FATOR & MSPA & MSR & RRPA & PAC & PDS $^{1}$ \\
\hline Fonte de P (1) & \multicolumn{2}{c}{$---\mathrm{g} \mathrm{vaso}^{-1}-----$} & & $\mathrm{mg} \mathrm{vaso}^{-1}$ & $\mathrm{mg} \mathrm{kg}^{-1}$ \\
\hline Testemunha & 0,080 & $0,043 \mathrm{~b}$ & 0,62 & 0,039 & $0,86 \mathrm{c}$ \\
Arad & 0,099 & $0,049 \mathrm{~b}$ & 0,64 & 0,045 & $2,99 \mathrm{~b}$ \\
SFT & 0,171 & $0,066 \mathrm{a}$ & 0,38 & 0,059 & $6,22 \mathrm{a}$ \\
\hline Valor de F & $21,80^{* *}$ & $6,96^{* *}$ & $11,99^{* *}$ & $3,07^{\text {ns }}$ & $105,17^{* *}$ \\
\hline Espécie (2) & & & & \\
\hline Braquiária & 0,063 & $0,025 \mathrm{~b}$ & 0,50 & $0,031 \mathrm{~b}$ & 3,30 \\
Sorgo & 0,073 & $0,041 \mathrm{~b}$ & 0,64 & $0,039 \mathrm{~b}$ & 3,26 \\
Milheto & 0,064 & $0,022 \mathrm{~b}$ & 0,57 & $0,028 \mathrm{~b}$ & 3,80 \\
Soja & 0,267 & $0,122 \mathrm{a}$ & 0,47 & $0,092 \mathrm{a}$ & 3,09 \\
\hline Valor de F & $63,46^{* *}$ & $70,15^{* *}$ & $1,94^{\text {ns }}$ & $19,00^{* *}$ & $0,63^{\text {ns }}$ \\
\hline Interação 1 x 2 & $3,58^{* *}$ & $1,60^{\text {ns }}$ & $2,42^{*}$ & $1,95^{\text {ns }}$ & $0,38^{\text {ns }}$ \\
\hline CV (\%) & 4,3 & 2,2 & 9,4 & 2,8 & 15,5 \\
\hline
\end{tabular}

Dentro de cada fator, médias seguidas de letras distintas na coluna diferem entre si pelo teste de Tukey a 5\% de significância.

${ }^{1}=$ fósforo disponível no solo, extraído por resina trocadora de íons (TEDESCO et al., 1995).

* = significativo a $5 \%$ de probabilidade de erro pelo teste $\mathrm{F}$.

** = significativo a $1 \%$ de probabilidade de erro pelo teste $\mathrm{F}$.

ns = não significativo a $5 \%$ de probabilidade de erro pelo teste $\mathrm{F}$.

Arad $=$ fosfato natural reativo de Arad.

SFT $=$ superfosfato triplo.

Fonte: Elaboração dos autores.

Tabela 2. Interação entre fontes de fósforo e espécies vegetais para as variáveis massa seca de parte aérea (MSPA) e relação raiz/parte aérea (RRPA).

\begin{tabular}{|c|c|c|c|c|}
\hline \multirow{2}{*}{ Fonte de $\mathrm{P}$} & \multicolumn{4}{|c|}{ Espécie } \\
\hline & Braquiária & Sorgo & Milheto & Soja \\
\hline & \multicolumn{4}{|c|}{$\operatorname{MSPA}\left(\mathrm{g}\right.$ vaso $\left.^{-1}\right)$} \\
\hline Testemunha & $0,027 \mathrm{bB}$ & $0,036 \mathrm{bB}$ & $0,013 \mathrm{bB}$ & $0,246 \mathrm{aA}$ \\
\hline Arad & $0,037 \mathrm{bB}$ & $0,047 \mathrm{bB}$ & $0,014 \mathrm{bB}$ & $0,295 \mathrm{aA}$ \\
\hline \multirow[t]{2}{*}{ SFT } & $0,124 \mathrm{aB}$ & $0,137 \mathrm{aB}$ & $0,163 \mathrm{aB}$ & $0,259 \mathrm{aA}$ \\
\hline & \multicolumn{4}{|c|}{ RRPA } \\
\hline Testemunha & $0,65 \mathrm{aA}$ & $0,71 \mathrm{aA}$ & $0,62 \mathrm{aA}$ & $0,51 \mathrm{aA}$ \\
\hline Arad & $0,51 \mathrm{abAB}$ & $0,74 \mathrm{aAB}$ & $0,84 \mathrm{aA}$ & $0,45 \mathrm{aB}$ \\
\hline SFT & $0,34 \mathrm{bA}$ & $0,47 \mathrm{aA}$ & $0,24 \mathrm{bA}$ & $0,46 \mathrm{aA}$ \\
\hline
\end{tabular}

Médias seguidas de letras distintas, minúsculas na coluna e maiúsculas na linha, diferem entre si pelo teste de Tukey a 5\% de significância.

Arad $=$ fosfato natural reativo de Arad.

SFT $=$ superfosfato triplo.

Fonte: Elaboração dos autores. 
Para a RRPA, as fontes de $\mathrm{P}$ apresentaram comportamento diferenciado entre as espécies, não havendo respostas do sorgo e da soja às fontes para esta variável (Tabela 2). Para braquiária, maiores valores foram observados no tratamento testemunha, e os menores no SFT, enquanto a aplicação de Arad proporcionou valores intermediários sem diferir dos demais tratamentos. Com o cultivo do milheto, observou-se diminuição na RRPA com a utilização de SFT. Esses dados reafirmam a idéia de que, sob deficiência de $\mathrm{P}$ no solo, as plantas (braquiária e milheto, neste experimento) produzem maior sistema radicular em detrimento da parte aérea, e assim podem aumentar a capacidade de absorção de $\mathrm{P}$, tendo em vista a baixa mobilidade deste elemento no solo. Segundo Fernandes e Souza (2006), este aumento da RRPA ocorre porque, após a absorção, o íon fosfato é deslocado por via simplástica e, sob deficiência, a demanda metabólica ao longo desta via retira o $\mathrm{P}$ da rota de deslocamento e o incorpora ao metabolismo das células da raiz, resultando em crescimento proporcionalmente maior das raízes em comparação com a parte aérea.

$\mathrm{O}$ fósforo acumulado no tecido (PAC) não foi influenciado pelas fontes de $\mathrm{P}$ avaliadas, provavelmente pelo elevado PAC da soja, independente da fonte fosfatada. Na comparação entre as espécies, maior valor de PAC foi encontrado com o cultivo da soja $\left(0,092 \mathrm{mg}\right.$ vaso $\left.^{-1}\right)$, enquanto o sorgo $\left(0,039 \mathrm{mg}\right.$ vaso $\left.^{-1}\right)$, a braquiária $(0,031 \mathrm{mg}$ vaso $\left.^{-1}\right)$ e o milheto $\left(0,028 \mathrm{mg} \mathrm{vaso}^{-1}\right)$ não diferiram entre si (Tabela 1). Ao observarmos a quantidade de $\mathrm{P}$ na semente de cada espécie (soja - 0,465 mg semente $^{-1}$, braquiária $-0,023 \mathrm{mg}$ semente ${ }^{-1}$, sorgo 0,064 mg semente ${ }^{-1}$, e milheto $-0,021 \mathrm{mg} \mathrm{semente}^{-1}$ ), verificamos que o PAC da soja representou apenas $20 \%$ do total presente na semente, enquanto que o PAC do sorgo, da braquiária e do milheto representou 61,135 e $133 \%$ do P na semente, respectivamente. Como valores acima de $100 \%$ indicam que parte do $\mathrm{P}$ no tecido é proveniente de outra fonte a não ser a semente, podemos observar maior capacidade de extração de $\mathrm{P}$ do solo pela braquiária e pelo milheto, mesmo no início de seu desenvolvimento.
Maior valor de fósforo disponível no solo (PDS) extraído por resina, foi alcançado com a aplicação de SFT (6,22 $\left.\mathrm{mg} \mathrm{kg}^{-1}\right)$, enquanto a utilização de Arad e o tratamento testemunha proporcionaram valores de PDS de 2,99 mg kg-1 e $0,86 \mathrm{mg} \mathrm{kg}^{-1}$, respectivamente (Tabela 1). Como esperado, o PDS não foi influenciado pelo cultivo de diferentes espécies.

O cálculo da eficiência relativa (ER) do Arad comparativamente ao SFT em cada cultura, com base na quantidade de $\mathrm{P}$ acumulada no tecido, demonstrou que apenas a braquiária e o milheto responderam positivamente à aplicação do fosfato natural, atingindo valores de ER de $51 \%$ e $8 \%$, respectivamente. A soja e o sorgo apresentaram valores negativos de ER, indicando ausência de incremento no acúmulo de $\mathrm{P}$ com a aplicação do fosfato natural. Deste modo, observamos a expressiva capacidade da braquiária em elevar seu PAC em comparação com as demais espécies, demonstrando assim seu potencial de absorção de $\mathrm{P}$ quando aplicada uma fonte de baixa solubilidade como o fosfato natural reativo de Arad. Esta característica é desejável para plantas de cobertura cultivadas em solos com a aplicação de fosfatos naturais, cuja finalidade seja a ciclagem de fósforo. Foloni et al. (2008), comparando o desenvolvimento e acúmulo de $\mathrm{P}$ de diversas espécies de plantas quando aplicados fosfatos naturais, também verificaram grande absorção de $\mathrm{P}$ com o cultivo da braquiária. No entanto, é valido ressaltar que a braquiária apresenta lento desenvolvimento inicial, característica esta, que poderá ser limitante a sua utilização como planta de cobertura em solos de cerrado fertilizados com fosfato natural, quando não houver tempo hábil para seu desenvolvimento, como no caso da colheita de cultivares tardias de soja na região centro-oeste do país, devido à escassez de chuvas a partir do mês de abril. Outra limitação na utilização da braquiária como planta de cobertura visando à ciclagem de nutrientes, referese a baixa taxa de decomposição dos resíduos desta espécie, sendo esta característica responsável pela 
lenta mineralização dos nutrientes presentes no tecido. Deste modo, os efeitos da utilização da braquiária como planta de cobertura na ciclagem de nutrientes poderão ser observados apenas em longo prazo. Para contornar estes possíveis problemas do cultivo da braquiária, seria recomendado utilizar o milheto como planta de cobertura, pois também demonstrou um índice positivo de aproveitamento relativo do Arad, embora menor que o da braquiária, e segundo Foloni et al. (2008), apresenta rápido desenvolvimento inicial que proporciona bom acúmulo de fitomassa antes do início da escassez das chuvas.

De modo geral, uma das explicações para a baixa eficiência do fosfato natural reativo de Arad é a pouca acidez e o moderado teor de Ca do solo, características estas alcançadas com a calagem efetuada antes da instalação do experimento, e que dificultam a solubilização do fosfato natural (GATIBONI et al., 2003; GUIDRY; MACKENZIE, 2003; AGBENIN, 2004). No entanto, no presente estudo, justificou-se a aplicação de calcário para elevar a saturação por bases do solo, conforme recomendado por Sousa e Lobato (2004), a fim de mantermos apenas a deficiência de $\mathrm{P}$ como fator limitante para o desenvolvimento das culturas. Outro fator comumente citado como determinante na elevação da eficiência de utilização de fosfatos naturais em relação aos fosfatos solúveis, é o tempo de aplicação. As fontes de $\mathrm{P}$ de alta solubilidade, ao disponibilizarem praticamente todo o $\mathrm{P}$ em curto prazo, favorecem a adsorção específica de grande parte do $\mathrm{P}$, caso este não seja absorvido. Isto não ocorre com os fosfatos de menor solubilidade, os quais necessitam da remoção tanto de $\mathrm{P}$ como de Ca da solução do solo para que mantenham sua solubilização e possam favorecer a produção das culturas através de cultivos sucessivos, conforme relatado por Moreira, Malavolta e Moraes (2002) e Gatiboni et al. (2003).
Houve diferença entre as espécies para o influxo máximo de $\mathrm{P}\left(\mathrm{I}_{\max }\right)$ e para a concentração mínima de nutriente na solução para que ocorra absorção $\left(\mathrm{C}_{\text {min }}\right)$, enquanto a concentração de nutriente na solução em que ocorre a metade do $\mathrm{I}_{\text {max }}\left(\mathrm{K}_{\mathrm{m}}\right)$, não diferiu entre as espécies (Figura 1). Para $\mathrm{I}_{\max }$, a braquiária apresentou maiores valores em relação à soja, enquanto o sorgo e o milheto apresentaram valores intermediários, sem diferir de ambos os extremos. Embora não tenham sido encontradas diferenças entre o $\mathrm{K}_{\mathrm{m}}$ das plantas, Horn et al. (2006) alerta que menores valores de $\mathrm{K}_{\mathrm{m}}$ são sempre desejáveis numa planta eficiente na absorção de P. Entretanto, alguns trabalhos têm demonstrado que a principal alteração nos parâmetros cinéticos das plantas em resposta a deficiência de $\mathrm{P}$ é a elevação nos valores de $\mathrm{I}_{\text {max }}$, enquanto o $\mathrm{K}_{\mathrm{m}}$ tem sido pouco alterado (ALVES et al., 2002; BHADORIA et al., 2004). Como o valor isolado do $\mathrm{I}_{\max }$ só terá importância quando ocorrerem elevadas concentrações de nutriente na solução, e não houve diferenças entre os valores de $\mathrm{K}_{\mathrm{m}}$, realizamos o cálculo da relação $\mathrm{I}_{\max } / \mathrm{K}_{\mathrm{m}}$, que segundo Brix et al. (2010), representa a afinidade dos carregadores com o nutriente, e obtivemos os valores de 6,07, 2,53, 2,56, 2,15, para braquiária, milheto, soja e sorgo, respectivamente. A importância desse maior valor obtido pela braquiária em comparação com as demais espécies pode ser observada nas curvas de absorção de $\mathrm{P}$ (Figura 1), indicando que esta gramínea apresenta carregadores com alta afinidade por este nutriente. Esta afinidade pode ser responsável pela maior eficiência relativa do fosfato natural de Arad com o cultivo de braquiária, tendo em vista o significativo aumento na taxa de absorção de $\mathrm{P}$ desta espécie com a elevação da concentração do nutriente na solução, conforme ocorrido com a aplicação do fosfato natural no primeiro experimento. 
Figura 1. Valores de influxo máximo de fósforo $\left(\mathrm{I}_{\max }, \mu \mathrm{mol} \mathrm{g}^{-1} \mathrm{~h}^{-1}\right)$, concentração de fósforo na solução em que ocorre a metade do $I_{\max }\left(\mathrm{K}_{\mathrm{m}}, \mu \mathrm{mol} \mathrm{L} \mathrm{L}^{-1}\right)$, concentração mínima de fósforo na solução para que ocorra absorção $\left(\mathrm{C}_{\min }, \mu \mathrm{mol}\right.$ $\left.\mathrm{L}^{-1}\right)$ e curvas de absorção de fósforo de soja, milheto, braquiária e sorgo. Para cada variável, médias seguidas de letras distintas diferem entre si pelo teste de Tukey a $5 \%$ de significância. Coeficientes de variação: $\mathrm{I}_{\max }=37 \%, \mathrm{~K}_{\mathrm{m}}=42 \%$, e $\mathrm{C}_{\min }=38 \%$.

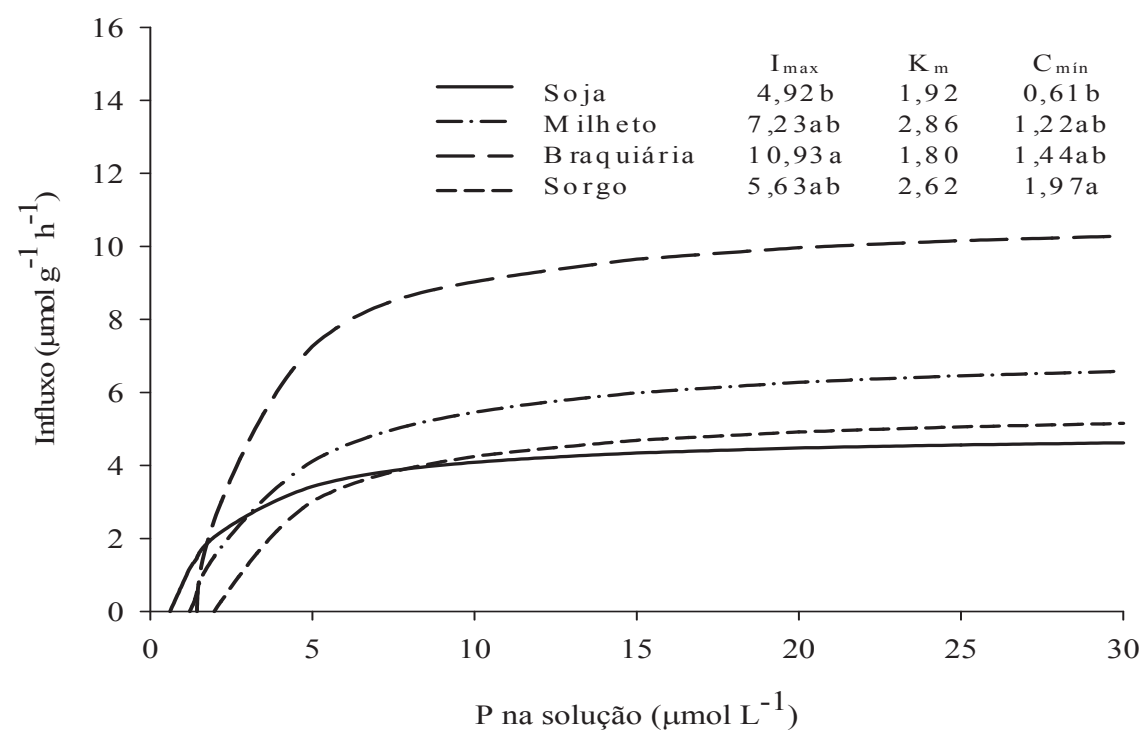

Fonte: Elaboração dos autores.

Para o $\mathrm{C}_{\text {mín }}$, a soja apresentou menores valores em relação ao sorgo, enquanto o milheto e a braquiária não diferiram das outras espécies. De acordo com Horn et al. (2006), quando não há limitação na chegada dos nutrientes às raízes, o $\mathrm{C}_{\text {mín }}$ não tem muita importância, pois não limita a absorção, contudo, quando o suprimento pelo solo é pequeno, como ocorre em solos com baixa concentração de nutrientes ou em períodos de déficit hídrico, o $\mathrm{C}_{\min }$ exerce grande influência na absorção. Deste modo, sob condições de disponibilidade restrita de $\mathrm{P}$ no solo, a soja poderá apresentar maior capacidade de absorção de $\mathrm{P}$ quando comparada as demais espécies avaliadas.

Como a concentração de $\mathrm{P}$ na solução do solo é variável tanto espacialmente, como no caso da aplicação de fertilizantes onde haverá altas concentrações de $\mathrm{P}$ próximos aos grânulos de adubo, como temporalmente, quando há maior ou menor umidade do solo, o $I_{\max }$ pode ser o parâmetro mais importante no acúmulo de nutrientes pelas plantas quando comparado ao $\mathrm{C}_{\text {mín. }}$ Isto ocorre porque, em micro-regiões do solo ou em períodos de alta concentração de $\mathrm{P}$, as plantas com maior $\mathrm{I}_{\max }$ poderão absorver grandes quantidades deste nutriente. Entretanto, plantas com baixo $\mathrm{C}_{\text {min }}$ terão lenta, mas contínua absorção de $\mathrm{P}$ mesmo em baixas concentrações na solução, porém, dependendo do período de atuação do $\mathrm{C}_{\text {mín }}$, a quantidade acumulada poderá não equivaler a absorvida pelas plantas com maior $\mathrm{I}_{\max }$.

Assim, com base nos resultados apresentados podemos concluir que: a soja, em seu desenvolvimento inicial, não responde à aplicação de fósforo ao solo; dentre as plantas de cobertura, a braquiária tem maior capacidade de absorção de $\mathrm{P}$ em solo fertilizado com fosfato reativo de Arad e pode ser indicada como recicladora deste nutriente nestas condições e; a braquiária apresenta maior taxa de absorção de P em elevadas concentrações 
deste nutriente na solução, enquanto a soja apresenta maior capacidade de absorção de $\mathrm{P}$ em baixas concentrações na solução.

\section{Agradecimentos}

À Capes e ao CNPq pela concessão de bolsas aos autores.

\section{Referências}

AGBENIN, J. O. Free energy and kinetics of dissolution of sokoto rock phosphate and the implications for replenishing phosphorus in the savanna soil of Nigeria. European Journal of Soil Science, Oxford, v. 55, n. 1, p. 55-61, 2004.

ALVES, V. M. C.; PARENTONI, S. N.; VASCONCELLOS, C. A.; PITTA, G. V. E.; FRANÇA, C. C. M. Cinética de absorção de fósforo e crescimento do sistema radicular de genótipos de milho contrastantes para eficiência a fósforo. Revista Brasileira de Milho e Sorgo, Sete Lagoas, v. 1, n. 1, p. 85-92, 2002.

ARCAND, M. M.; SCHNEIDER, K. D. Plant- and microbial-based mechanisms to improve the agronomic effectiveness of phosphate rock: a review. Annals of the Brazilian Academy of Sciences, Rio de Janeiro, v. 78, n. 4, p. 791-807, 2006.

BANZATO, D. A.; KRONKA, S. N. Experimentação agrícola. 4. ed. Jaboticabal: FUNEP, 2006. 237 p.

BHADORIA, P. S.; DESSOUGI, H. E.; LIEBERSBACH, H.; CLAASSEN, N. Phosphorus uptake kinetics, size of root system and growth of maize and groungnut in solution culture. Plant and Soil, The Hague, v. 262, n. 1-2, p. 327-336, 2004.

BRIX, H.; LORENZEN, B.; MENDELSSOHN, I. A.; MCKEE, K. L.; MIAO, S. Can differences in phosphorus uptake kinetics explain the distribution of cattail and sawgrass in the Florida Everglades? BMC Plant Biology, London, v. 10, n. 23, p. 1-14, 2010.

CLAASSEN, N.; BARBER, S. A. A method for characterizing the relation between nutrient concentration and flux into roots of intact plants. Plant Physiology, Illinois, v. 54, n. 4, p. 564-568, 1974.

FERNANDES, M. S.; SOUZA, S. R. Absorção de nutrientes. In: FERNANDES, M. S. (Ed.). Nutrição mineral de plantas. Viçosa: SBCS, 2006. p. 115-152.

FOLONI, J. S. S.; TIRITAN, C. S.; CALONEGO, J. C.; ALVES JUNIOR, J. Aplicação de fosfato natural e reciclagem de fósforo por milheto, braquiária, milho e soja. Revista Brasileira de Ciência do Solo, Viçosa, MG, v. 32, n. 3, p. 1147-1155, 2008.

GATIBONI, L. C.; KAMINSKI, D. S.; RHEINHEIMER, D. S.; BRUNETTO, G. Superphosphate and rock phosphates as phosphorus sources for grass-clover pasture on a limed acid soil in southern Brazil. Communications in Soil Science and Plant Analysis, New York, v. 34, n. 17-18, p. 2503-2514, 2003.

GUIDRY, M. W.; MACKENZIE, F. T. Experimental study of igneous and sedimentary apatite dissolution: Control of $\mathrm{pH}$, distance from equilibrium, and temperature on dissolution rates. Geochimica et Cosmochimica Acta, Saint Louis, v. 67, n. 16, p. 2949-2963, 2003.

HOAGLAND, D. R.; ARNON, D. I. The water-cultured method for growing plants without soil. California: California Agricultural Experiment Station, 1950. 32 p. (Circular, 347).

HORN,D.;ERNANI,P.R.; SANGOI,L.; SCHWEITZER, C.; CASSOL, P. C. Parâmetros cinéticos e morfológicos da absorção de nutrientes em cultivares de milho com variabilidade genética contrastantes. Revista Brasileira de Ciência do Solo, Viçosa, MG, v. 30, n. 1, p. 77-85, 2006.

MOREIRA, A.; MALAVOLTA, E.; MORAES, L. A. C. Eficiência de fontes e doses de fósforo na alfafa e centrosema cultivadas em Latossolo Amarelo. Pesquisa Agropecuária Brasileira, Brasília, v. 37, n. 10, p. 14591466, 2002.

MURPHY, J.; RILEY, J. P. A modified single solution methods for the determination of phosphate in natural waters. Analytica Chimica Acta, Oxford, v. 27, n. 1, p. 31-36, 1962.

NYING, C. S.; ROBINSON, S. J. Factors influencing the dissolution of phosphate rock in a range of high P-fixing soils from Cameroon. Communications in Soil Science and Plant Analysis, New York, v. 37, n. 15-20, p. 26272645, 2006.

OLIVEIRA, T. K.; CARVALHO, G. J.; FURTINI NETO, A. N.; LIMA, P. C.; MORAES, R. N. S. Atributos químicos do solo sob diferentes plantas de cobertura na implantação do sistema plantio direto. Revista Agricultura Tropical, Cuiabá, v. 8, n. 1, p. 57-71, 2005.

RAMOS, S. J.; FAQUIN, V.; RODRIGUES, C. R.; SILVA, C. A.; ÁVILA, F. W.; SAMPAIO, R. A. Utilização de fósforo e produção de feijoeiro: influência de gramíneas forrageiras e fontes de fósforo. Revista Brasileira de Ciência do Solo, Viçosa, MG, v. 34, n. 1, p. 89-96, 2010. 
ROS, C.; BELL, R. W.; WHITE, P. F. Effect of seed phosphorus and soil phosphorus applications on early growth of rice (Oryza sativa L.) cv. IR66. Soil Science and Plant Nutrition, Tokyo, v. 43, n. 3, p. 499-509, 1997.

RUIZ, H. A.; FERNANDES FILHO, E. I. Cinética: Software para estimar as constantes $\mathrm{V}_{\max }$ e $\mathrm{K}_{\mathrm{m}}$ da equação de Michaelis-Menten. In: REUNIÂO BRASILEIRA DE FERTILIDADE DO SOLO E NUTRIÇÃO DE PLANTAS, 10., 1992. Piracicaba. Anais... Piracicaba: Sociedade Brasileira de Ciência do Solo, 1992. p. 124125.

SOUSA, D. M. G.; LOBATO, E. Calagem e adubação para culturas anuais e semiperenes. In: SOUSA, D. M. G.; LOBATO, E. (Ed.). Cerrado: correção do solo e adubação. 2. ed. Planaltina: Embrapa Cerrados, 2004. p. 283-316.
SOUSA, D. M. G.; LOBATO, E.; REIN, T. A. Adubação com fósforo. In: SOUZA, D. M. G.; LOBATO, E. (Ed.). Cerrado: correção do solo e adubação. 2. ed. Planaltina: Embrapa Cerrados, 2004. p. 147-168.

TEDESCO, M. J.; GIANELLO, C.; BISSANI, C. A.; BOHNEN, H.; VOLKWEISS, S. J. Análise de solo, plantas e outros materiais. Porto Alegre: UFRGS/FA/ DS, $1995.174 \mathrm{p}$.

TRIGO, L. F. N.; PESKE, S. T.; GASTAL, F. C.; VAHL, L. C.; TRIGO, M. F. O. Efeito do conteúdo de fósforo na semente de soja sobre o rendimento da planta resultante. Revista Brasileira de Sementes, Brasília, v. 19, n. 1, p. 111-115, 1997.

ZHU, Y. G.; SMITH, S. E. Seed phosphorus (P) content affects growth, and $\mathrm{P}$ uptake of wheat plants and their association with arbuscular mycorrhizal (AM) fungi. Plant and Soil, The Hague, v. 231, n. 1, p. 105-112, 2001. 
